\title{
O cinema na conquista da América: um filme e seus diálogos com a história
}

\author{
Roberto Abdala Junior
}

Centro Universitário do Leste de Minas Gerais, Cursos de História e Pedagogia Universidade Federal de Minas Gerais, Programa de Pós-Graduação em História

Se os historiadores estão procurando modelos de narrativas que justaponham as estruturas da vida comum pelos acontecimentos extraordinários, e a visão de baixo pela de cima, podem muito bem ser aconselhados a voltar à ficção do século vinte, incluindo o cinema...

Burke, 1992, p. 347

\section{Introdução}

O trabalho que ora apresentamos consiste em uma pequena argumentação teórica, seguida de um exercício de aplicação de proposições que formulamos em nossa dissertação de mestrado. Naquela ocasião estávamos empenhados em encontrar abordagens teóricas que pudessem esclarecer algumas relações entre história e cinema que pudessem contribuir nos processos de construção de conhecimentos históricos escolares, nos quais os filmes figurassem como mediadores.

A intenção era que o trabalho resultasse numa ampliação do emprego de filmes nas aulas de história, levando as mídias audiovisuais a entrar para o horizonte cultural dos alunos. A finalidade última, entretanto, era que assim estivéssemos ajudando os nossos alunos a criarem ferramentas para leituras do mundo contemporâneo, cujos significados dos acontecimentos se têm transformado, muito em função das mídias audiovisuais.

A maneira mais precisa para iniciarmos uma discussão sobre um tema tão visitado, e paradoxalmente tão pouco esclarecido, talvez seja parafrasear Robert Rosenstone. O historiador, depois de refletir sobre a trajetória histórica das relações humanas com o passado, tomando como eixo principal a inserção do cinema como mediador nesses processos, sentenciou: "o cinema muda as regras do jogo histórico", pois "as imagens são muito mais complexas que qualquer texto escrito" (1997, p. 22, tradução livre). Nesse contexto é que se inscreve o presente artigo. Noutras palavras, pretendemos oferecer elementos para que as relações entre cinema e história sejam iluminadas por outro viés teórico, evidenciando novos aspectos dos processos sociais que presidem essa interação, ou que, pelo menos, podem ser tomados como protocolos das interações sociais nas abordagens analíticas que pretendem estudá-las. 
O quadro teórico foi o grande desafio que enfrentamos, uma vez que análises de filmes são trabalhos corriqueiros em praticamente todos os campos das ciências humanas. Assim, a argumentação que apresentamos assentou-se, necessariamente, em teses de tradições acadêmicas distintas, nas quais, entretanto, é possível encontrar concordâncias significativas: de um lado a história cultural, e de outro a psicologia sociocultural, representadas pelas obras de Roger Chartier e de James Wertsch, respectivamente.

Os dois autores têm em comum o fato de serem reconhecidos internacionalmente pelas abordagens teóricas que formularam, além de desenvolverem pesquisas inovadoras nos campos de conhecimento em que atuam. $\mathrm{O}$ historiador da cultura tem pesquisado, entre outros temas, as práticas socioculturais de escrita e leitura na sociedade de corte francesa. O teórico da psicologia sociocultural vem refletindo sobre a complementaridade entre os conceitos formulados por L. S. Vygotsky e Mikhail Bakhtin, sugerindo possibilidades do emprego articulado das teses desses autores em pesquisas que têm os processos de ensinoaprendizagem como foco.

Chartier e Wertsch, não obstante a diversidade de objetos e do arsenal teórico a que recorrem, consideram a cultura como ambiente de construção dos significados do mundo da experiência (histórica e/ou educacional), e tomam os bens culturais como ferramentas que os homens empregam nas suas práticas sociais. Nesse sentido, consideramos que ambos, em que pesem as demandas teóricas de seus respectivos objetos de estudo, recorrem a premissas que os aproximam de maneira surpreendente. ${ }^{1}$

${ }^{1}$ Wertsch, em um de seus últimos trabalhos, tem como foco as lembranças coletivas de adolescentes que experimentaram as transformações ocorridas na transição da antiga União Soviética para Rússia (2002). Noutra obra o autor emprega pesquisas sobre alunos estadunidenses e soviéticos em suas reflexões sobre a construção do conhecimento histórico, apresentando o significado das narrativas nesses processos (1999). Ao analisar as "lembranças coletivas", ou lidando com diversas pesquisas no campo da edu-
O caso do cinema parece-nos ainda mais importante na argumentação. As reflexões sobre as possibilidades de análise da linguagem cinematográfica pautaram-se nas teses de Bakhtin - sugeridas por alguns pesquisadores para superar limitações de outros enquadramentos teóricos (Stam, 1992). Assim, sugerimos que, além de apreender a linguagem cinematográfica, as teses bakhtinianas - conforme são empregadas na psicologia sociocultural ${ }^{2}$-, cotejadas com a argumentação de teóricos do cinema como Jean Mitry e Jacques Aumont, contribuem para apreendermos também possibilidades de apropriação de um filme pelo público.

Uma incursão nas obras desses autores permitenos defender então o emprego de conceitos bakhtinianos como eixo orientador para a análise de dois processos diferentes: primeiramente, nas interações entre o público e o filme, considerando os contextos socioculturais e históricos nos quais acontece a exibição; também na leitura/apreensão da diegese fílmica, buscando compreender os discursos construídos pelos filmes a partir das interações entre os elementos que compõem a linguagem cinematográfica. ${ }^{3}$ Nosso argumento, apesar de inicialmente parecer inovador, somente emprega as reflexões apresentadas por James Wertsch a um objeto diferente - o cinema -, tomando o cuidado de reconhecer a especificidade que lhe é própria - sua linguagem.

\section{Discursos: os significados contextualizados segundo Bakhtin}

O historiador francês Roger Chartier faz uma extensa argumentação para apresentar as premissas

cação em seus trabalhos, Wertsch não parece formular uma reflexão muito distante da que aqui desenvolvemos, apesar de o autor não empregar textos audiovisuais. A questão da necessidade de reconhecimento e da resistência às aproximações e paralelismos teóricos entre diversas disciplinas acadêmicas é abordada por Wertsch especialmente no primeiro capítulo de La mente en acción (1999).

${ }^{2}$ Apoiamos este argumento nos trabalhos de Wertsch, especialmente em sua obra La mente em acción (1999, p. 47).

\footnotetext{
${ }^{3}$ Sugestão de Stam (1992), citada a seguir.
} 
teóricas nas quais se assentam os trabalhos reunidos na sua obra História cultural: entre práticas e representações (1989). Ao refletir sobre a história cultural, considera que tem por principal objeto "identificar o modo como em diferentes lugares e momentos uma determinada realidade social é construída, pensada, dada a ler". Assim, a história cultural para Chartier deve ser "entendida como o estudo dos processos com os quais se constrói um sentido" (p. 16-17) e dirigirse às "práticas que pluralmente, contraditoriamente, dão significado ao mundo" (p. 27). Mas, para que se possa realizar uma abordagem dessa natureza, é necessário contar com um instrumento teórico-metodológico eficaz, pois

A problemática do "mundo como representação", moldado através das séries de discursos que o apreendem e o estruturam, conduz obrigatoriamente a uma reflexão sobre o modo como uma figuração desse tipo pode ser apropriada pelos leitores dos textos (ou das imagens) que dão a ver e a pensar o real. (idem, p. 23-24, grifo nosso)

O historiador, ao referir-se ao "mundo como representação", está considerando que sua "construção" se dá fundamentalmente no campo simbólico e, nesse sentido, é "moldado através das séries de discursos que o apreendem e estruturam". No entanto, discursos podem ser enunciados por meio de diversas linguagens, mas para se constituírem como tais requerem a existência de um meio (suporte) de expressão para serem compartilhados. Nesse aspecto, as reflexões de Chartier não diferem daquelas que encontramos em trabalhos de psicólogos socioculturais. Uma resposta à questão apresentada por Chartier pode então nascer a partir das reflexões de Wertsch.

Ao debruçar-se sobre as obras de Vygotsky e Bakhtin, Wertsch apontou "aproximações conceituais", para empregar seus próprios termos, nos aspectos concernentes ao emprego de signos e discursos pelos indivíduos. Segundo o autor, ambos consideram que o emprego do material semiótico, as "ferramentas culturais" (Wertsch, 1999, 2002) disponíveis na cultura são organizadoras do subjetivismo individual. Decorre dessa premissa que a configuração da consciência, da memória - individual e social - e a realização do aprendizado são processos que nascem a partir das interações sociais mediadas por ferramentas culturais.

Ancorado nos argumentos de Vygotsky e Bakhtin, Wertsch defende outra maneira de abordar a psicologia individual. Rompendo com o conceito de sujeito universal que caracteriza outras abordagens, o psicólogo considera necessário "elaborar uma explicação dos processos mentais que reconheça a relação essencial entre estes processos e seus cenários culturais, históricos e institucionais". O autor pretende "seguir uma proposta mais geral, segundo a qual os instrumentos mediadores surgem em resposta a uma extensa série de forças sociais" (1993, p. 23).

A partir dessa premissa, Wertsch considera que "é a ação, mais do que os seres humanos ou o ambiente, considerados isoladamente, que proporciona o ponto de entrada para uma análise" (1993, p. 25). Para ele, "a ação tipicamente humana emprega 'instrumentos mediadores' tais como ferramentas ou linguagem e estes instrumentos mediadores dão forma a ação de maneira essencial" (1993, p. 29). No entanto, Wertsch concebe a "ação humana" de maneira diferenciada. Segundo o autor:

Os tipos de referenciais que tenho em mente podem ser encontrados nos trabalhos de escritores russos e soviéticos, como Bakhtin... enfocando o enunciado como forma de ação; Vygotsky... com ênfase no discurso do pensamento e mais genericamente na "ação mediada". ${ }^{4}$ Um ponto

${ }^{4} \mathrm{O}$ conceito de "ação mediada" refere-se às ações cognitivas e/ou práticas, realizadas por meio dos "mediadores semióticos", ou seja, ações que exigem um processo qualquer de aprendizagem para serem realizadas ("Estudos socioculturais: história, ação e mediação", in Wertsch, 1998, p. 107-121). No trabalho que lida com as "lembranças coletivas", o autor emprega a noção de "ferramentas culturais" - termo mais próximo ao uso que fazemos dele aqui -, que estaria ligada ao seguinte argumento de Vygotsky: "A invenção e o uso de signos como meios auxiliares 
comum de convivência entre todos esses autores são seus enfoques na ação humana concreta e dinâmica que ocorre em contextos reais, espaço-temporais e sociais. (Wertsch, 1998, p. 60-61, grifo nosso)

Nesse trecho Wertsch remete-nos às reflexões de Chartier sobre um conceito central de sua argumentação: o de apropriação. Segundo o historiador, a noção de apropriação deve ser "colocada no centro de uma abordagem de história cultural que se prende com práticas diferenciadas, com utilizações contrastadas" (Chartier, 1989, p. 26). Assim, o historiador da cultura define o conceito de apropriação como tendo

[...] por objetivo uma história social das interpretações, remetidas para as suas determinações fundamentais (que são sociais, institucionais, culturais) e inscritas nas práticas especificas que as produzem. Conceder deste modo atenções às condições e aos processos que, muito concretamente, determinam as operações de construção do sentido (na relação de leitura, mas em muitas outras também) é reconhecer [...] que as categorias aparentemente mais invariáveis devem ser construídas na descontinuidade das trajetórias históricas. (idem, p. 27, grifos nossos)

Os autores não estão, pois, preocupados com as ferramentas representacionais (ou representações) em si, mas com a "ação" concreta realizada nas práticas sociais pelos sujeitos que as empregam. Ambos perseguem formas de compreender as condições e os processos "que, muito concretamente, determinam as operações de construção do sentido (na relação de

para solucionar um dado problema psicológico (lembrar, comparar coisas, relatar, escolher etc.) é análoga à invenção e uso de instrumentos, só que agora no campo psicológico. O signo age como um instrumento da atividade psicológica de maneira análoga ao papel de um instrumento no trabalho" (Vygotsky, 1994, p. 70, grifo nosso). Nesse argumento também encontramos o significado das "ferramentas culturais" nos processos de aprendizagem que estejam assentados na formulação de problemas, tal como propomos a seguir. leitura, mas em muitas outras também)", sendo que o diferencial apresentado em seus respectivos argumentos se baseia em reconhecer que essas categorias "devem ser construídas na descontinuidade das trajetórias históricas", pois somente aí, na "ação humana concreta e dinâmica que ocorre em contextos reais, espaços-temporais e sociais", os significados do "mundo como representação" podem ser apreendidos (Chartier, 1989, p. 26-27). Assim, mesmo que em campos distintos, Chartier e Wertsch têm em mente que uma análise que enfoque as interpretações do mundo, tomando as ferramentas que pretendem representálas, somente tem sentido na medida em que são reconhecidas as práticas nas quais os homens que as realizam estão engajados.

A contribuição de Bakhtin torna-se essencial à análise, precisamente porque seus trabalhos visam apreender os significados atribuídos ao mundo não a partir dos signos ou dos discursos isolados, mas segundo o enunciado ${ }^{5}$ completo no qual estão envolvidos, ou seja, a partir do contexto sociocultural e histórico no qual o enunciado se realiza concretamente. Assim, as teses de Mikhail Bakhtin, conforme esperamos demonstrar, abrem possibilidades de reconhecermos muitas das relações que se estabelecem entre os discursos da história e do cinema em diversos contextos socioculturais.

\section{O enunciado: discursos e diálogos em contextos definidos}

Mikhail Bakhtin foi um pensador soviético contemporâneo do psicólogo Vygotsky e do cineasta Eisenstein, mas que teve seus trabalhos publicados no Ocidente somente na segunda metade do século XX. No sentido de apreender os processos humanos dos quais a linguagem participa, Bakhtin privilegiou em suas reflexões a ação de enunciação e procurou

${ }^{5}$ Ressaltamos que o enunciado, em Bakhtin, tem um significado muito preciso, constituindo-se, como veremos a seguir, em um conceito fundamental para apreendermos suas teses. 
demonstrar que todos os discursos se caracterizam por serem dialógicos. Os autores que têm mergulhado nas obras do autor consideram que o conceito de dialogismo ${ }^{6}$ é central nas suas proposições porque é ele que converte o foco da análise dos discursos para o enunciado, ${ }^{7}$ pretendendo esclarecer as relações que se estabelecem entre texto e contexto. Nesse sentido, Bakhtin emprega o termo "tema", e explica:

Um sentido definido único, uma significação unitária, é uma propriedade que pertence a cada enunciação como um todo. Vamos chamar o sentido da enunciação completa o seu tema. [...] Ele se apresenta como a expressão de uma situação histórica concreta que deu origem à enunciação. [...] Conclui-se que o tema da enunciação é determinado não só pelas formas lingüísticas que entram na composição (as palavras, as formas morfológicas ou sintáticas, os sons, as entonações), mas igualmente pelos elementos não verbais da situação. (Bakhtin, 1997, p. 128)

Neste trabalho, como o emprego dos conceitos bakhtinianos está voltado para a compreensão das sig-

${ }^{6}$ Estamos empregando o conceito de dialogismo como sugere Stam (1992, p. 33-34): "Bakhtin, caracteristicamente, estende o sentido de interação verbal, que é apenas outra denominação para ‘diálogo', no sentido primário do discurso entre duas pessoas a outros domínios até mesmo metafóricos. Essa concepção ampla de dialogismo, considerada como o modo característico de um universo marcado pela heteroglossia, oferece inúmeras implicações para os estudos sobre cultura. [...] Esse conceito multidimensional e interdisciplinar do dialogismo, se aplicado a um fenômeno cultural como um filme, por exemplo, referir-se-ia não apenas ao diálogo dos personagens no interior do filme, mas também ao diálogo do filme com filmes anteriores, assim como ao 'diálogo' de gênero ou de vozes de classe no interior do filme, ou ao diálogo entre as várias trilhas (entre a música e a imagem, por exemplo). Além disso, poderia referir-se também ao diálogo que conforma o processo de produção especifico (entre produtor e diretor, diretor e ator), assim como às maneiras como o discurso cinematográfico é conformado pelo público, cujas reações potencias são levadas em conta".

${ }^{7}$ A esse respeito consultar Wertsch (1993, p. 74) e Stam (1992, p. 72). nificações sociocultural e historicamente contextualizadas dos discursos, remetemo-nos ao seu conceito de "tema", ${ }^{8}$ porque é no seu interior que encontraremos as significações (Bakhtin, 1997). Não empregaremos, entretanto, o termo "tema", mas o termo "enunciado". A escolha justifica-se porque a abordagem historiográfica (e também a da psicologia sociocultural, como vimos) busca saturar de "elementos nãoverbais" os contextos nos quais os enunciados se realizaram concretamente. Noutras palavras, um exercício de pesquisa histórica exige que a enunciação dos discursos seja sempre historicizada - apreendida no contexto histórico no qual se realizou a ação, para que o historiador possa reconhecer os significados históricos que carregam (Chartier, 1989, p. 63).

Segundo Bakhtin, os discursos, ao serem enunciados, estão realizando "diálogos" em dois contextos diferentes: um mais complexo e amplo, o da "comunicação cultural” - dos discursos científicos, artísticos, políticos etc. - e em outro, mais próximo, simples e restrito, com os quais dialoga mais imediatamente - o contexto dos interlocutores de seu grupo ou meio (Bakhtin, 1992). Os discursos apresentam

\footnotetext{
${ }^{8}$ Considerando a especificidade que as teses de Bakhtin apre-
} sentam, preferimos empregar seus próprios argumentos para explicar os termos "tema" e "significação" como aparecem em Marxismo e filosofia da linguagem (1997, grifos nossos): "O tema da enunciação é, na verdade, assim como a própria enunciação, individual e não-reiterável. Ele se apresenta como a expressão de uma situação histórica concreta que deu origem a enunciação" (p. 127). "Somente a enunciação tomada em toda a sua amplitude concreta, como fenômeno histórico, possui um tema" (p. 128). "A maneira mais correta de formular a inter-relação do tema e da significação é a seguinte: o tema constitui o estágio superior da capacidade lingüística de significar. A investigação da significação de um outro elemento lingüístico pode, segundo a definição que demos, orientar-se para duas direções: para o estágio superior, o tema; nesse caso, tratar-se-ia da investigação da significação contextual. Ou então ela pode tender para o estágio inferior, o da significação: a investigação da palavra dicionarizada" (p. 129, grifos do original). 
para o autor duas formas de apreciação: a entonação expressiva e a voz. No ato de enunciação, os discursos adquirem um acento próprio daquele que o enuncia: a "entonação expressiva" (idem). Um discurso escrito, por exemplo, recebe uma "entonação expressiva" todas as vezes que for proferido por um enunciador diferente. Existe, entretanto, uma apreciação mais significativa e que é própria de cada discurso: a "voz".

A "voz" do discurso expressa o juízo de valor do autor, seu horizonte conceitual (socioideológico). O discurso representa então uma escolha, uma tomada de posição do autor ante os múltiplos discursos que se pretendem apropriar/representar da/a realidade de uma época, num contexto sociocultural determinado. A essa apreciação - expressão do horizonte conceitual do autor do discurso - é que o pensador denomina "voz". Ao analisar a "voz" no romance, Bakhtin argumenta que:

Todas as palavras e formas que povoam a linguagem são vozes sociais e históricas, que lhe dão determinadas significações concretas e que se organizam no romance em um sistema estilístico harmonioso, expressando a posição sócio-ideológica diferenciada do autor no seio dos diferentes discursos da sua época. (Bakhtin, 1998, p. 106, grifo no original)

O grifo no texto é significativo para nossas reflexões, pois Bakhtin enfatiza assim que o autor do discurso não reproduz uma posição "socioideológica", mas realiza uma apropriação ${ }^{9}$ pessoal e diferenciada

${ }^{9}$ A idéia de apropriação que empregaremos corresponde a atitudes organizadas segundo "estratégias de distinção ou de imitação", considerando que "os empregos diversos dos mesmos bens culturais se enraízam nas disposições do habitus de cada grupo", como argumenta Chartier (1989, p. 137), mas enfatizando que o processo que é foco de nossa análise obedece ao que Michel de Certeau (2000) define como sendo o "consumo cultural das massas" - que, para Chartier, seria definido como uma "outra produção". Assim, a leitura de um texto, por exemplo, pode escapar à dos diferentes discursos que circulam numa época definida. Mais precisamente, segundo Bakhtin, a voz do discurso não somente se constitui e está articulada ao seu contexto de enunciação, como formula uma "reação responsiva" aos outros discursos, enunciados e/ou supostos, com os quais entra em diálogo nesse contexto. Bakhtin argumenta que

[...] em todas as direções, o discurso se encontra com o discurso de outrem e não pode deixar de participar, com ele, de uma interação viva e tensa. O discurso nasce no diálogo como sua réplica viva, forma-se na mútua-orientação dialógica no discurso de outrem no interior do objeto. A concepção que o discurso tem de seu objeto é a dialógica.

(Bakhtin, 1998, p. 88-89, grifo nosso)

A esse processo dialógico, de reação responsiva e recíproca entre os discursos, denominamos "interanimação dialógica das vozes dos discursos" ou, simplesmente, "interanimação dialógica" (Wertsch, 1993, 1998). A concepção é definida nos escritos de Bakhtin como uma aproximação que pudesse escapar às limitações dos campos de conhecimento, que, por isso, ele chamava de "translingüística".

Assim, a aplicação das teses de Bakhtin com a finalidade de objetivar e esclarecer os processos que se desenrolam entre os sujeitos/agentes sociais que empregam discursos em determinados contextos so-

passividade que tradicionalmente lhe é atribuída. "Ler, olhar ou escutar são, efetivamente, uma série de atitudes intelectuais que longe de submeterem o consumidor à toda-poderosa mensagem ideológica e/ou estética que supostamente o deve modelar - permitem na verdade a reapropriação, o desvio, a desconfiança ou resistência. Esta constatação deve levar a repensar totalmente a relação entre um público designado como popular e os produtos historicamente diversos (livros e imagens, sermões e discursos, canções, fotonovelas ou emissões de televisão) propostos para o seu consumo" (Chartier, 1989, p. 59-60). Nesse sentido, consideramos que o habitus de um grupo social modela mas não determina as maneiras de apreender a realidade concreta, abrindo sempre ao indivíduo possibilidades novas de apreendê-la e representá-la. 
cioculturais permitem-nos surpreendê-los no momento em que realizam, concretamente, a atribuição de significados ao mundo. Mais ainda, permitem uma análise do horizonte conceitual (ideológico) que pretenderam imprimir aos discursos que enunciaram e o sentido histórico que pretenderam conferir a eles.

\section{A linguagem cinematográfica e as teses de Bakhtin}

A idéia de que bens culturais estão abertos a múltiplas leituras, ou que uma obra é sempre polifônica, tem uma aceitação tão ampla na atualidade que poderia até ser considerada uma unanimidade. ${ }^{10} \mathrm{~A}$ idéia de polifonia, entretanto, não deve ser confundida: ela não sugere que as obras estejam abertas a todas as leituras. ${ }^{11}$ Muito ao contrário, na cultura encontramos protocolos de leitura que devem ser respeitados para que o "consumo" de bens culturais seja satisfatório - para que o processo de comunicação se realize a contento. Nesse sentido, parece decisivo que, ao lidar com cinema, a especificidade de sua linguagem seja não somente reconhecida, mas valorizada na análise, pois é ela que permite a construção e o compartilhamento dos discursos cinematográficos os filmes. ${ }^{12}$ A mesma preocupação levou-nos a tomar as teses de Bakhtin como diretrizes para uma proposta de leitura, também cinematográfica, dos filmes, na

${ }^{10}$ A respeito da impossibilidade de um diálogo realizado por meio das mídias, o argumento do próprio Bakhtin sugere essa possibilidade ao afirmar que "toda compreensão é prenhe de resposta e, de uma forma ou de outra, forçosamente a produz" (1992, p. 290). A noção de reação responsiva é, assim, uma contribuição teórica decisiva, por servir igualmente aos "diálogos" sociais e aos cognitivos.

${ }^{11}$ A esse respeito consultar, entre outros, Eco $(1991,1997)$ e Chartier (2001).

${ }^{12}$ Concebemos os filmes, antes de tudo, como narrativas: discursos que recorrem à linguagem cinematográfica para serem formulados. Os filmes são considerados assim por autores tão diversos como Metz (1980) e Maingueneau (2001). qual o foco da análise se volta para elementos que compõem a linguagem, privilegiando a imagem. ${ }^{13} \mathrm{~A}$ situação exigiu então que procurássemos cotejar as proposições bakhtinianas com reflexões de teóricos do cinema, especialmente Jean Mitry, cujos argumentos nos pareceram mais apropriados ao diálogo.

Mitry, em Estética y psicología del cine (1989), compara a significação da imagem do mundo da experiência à imagem fílmica e afirma que "A significação fílmica é completamente diferente. Nunca - ou raramente - depende de uma imagem isolada, e sim de uma relação entre as imagens, quer dizer, de uma implicação no sentido mais geral do termo" (1989, v. I, p. 133, tradução livre). As afirmações de Mitry remetem-nos às de Bakhtin, quando afirma que o significado do signo está "totalmente determinado por seu contexto. [e que] De fato, há tantas significações possíveis quantos contextos possíveis" (1997, p. 106).

Para Mitry (1989), a imagem fílmica não é uma representação do real, mas o real apresentado na tela, o que faz com que a imagem fílmica possa ser reconhecida pelos códigos culturais de leitura do mundo da experiência. Segundo o autor, o cinema apresenta, entretanto, uma diferença: as imagens, ao serem escolhidas para comporem uma cena e construírem a narrativa, adquirem uma significação específica. A escolha feita pelos realizadores, o enquadramento dado à imagem e suas relações com outras imagens que figuram no filme conferem um outro significado ao real apresentado na tela.

A argumentação anterior, em termos bakhtinianos, leva-nos a considerar que nas imagens filmicas o real recebe uma "entonação expressiva" própria do outro. Elas estão articuladas ao horizonte conceitual dos realizadores, constituindo-se e/ou compondo a sua voz. As imagens podem, ainda, fazer parte de um universo de outras vozes sobre as quais vai ressoar a $v o z$ dos realizadores (Bakhtin, 1992, 1997). Mitry (1989) afirma:

${ }^{13}$ As teses de Bakhtin têm sido empregadas para análise de filmes, de forma diferenciada, por autores como Robert Stam (1992) e Robert Burgoyne (2002). 
No cinema, ao contrário [da realidade], os objetos são apresentados sob um aspecto significativo. [...] este acento que se nos escapa na realidade é posto em evidência pela imagem fílmica, tanto mais quanto o que se acha implicado no filme é menos o objeto mesmo que um aspecto deste objeto, uma imagem. (v I, p. 143, tradução livre, grifo nosso)

A argumentação do autor oferece possibilidades de aplicarmos as proposições de Bakhtin no sentido de sugerir uma abordagem da linguagem cinematográfica conformando uma alternativa para a "leitura" do discurso que um filme constrói. Tomando a argumentação de Mitry como referência, podemos concluir que os códigos culturais de compreensão do real fornecem as chaves de leitura da narrativa imagética que os filmes compõem. Mas, as imagens empregadas em um filme recebem apreciações diferenciadas daquelas que têm na realidade, e seus significados são apreendidos segundo as relações que estabelecem com outras imagens no contexto da película. As imagens estão, assim, em interanimação dialógica com os outros elementos que compõem a narrativa cinematográfica.

As reflexões de Mitry, apreendidas pelo viés bakhtiniano, sugerem que a análise dos discursos cinematográficos deve considerar seus diálogos em dois contextos distintos: o contexto sociocultural e histórico de enunciação (de produção ou exibição) ${ }^{14}$ mais amplo, o da "comunicação cultural"; e outro mais restrito, o do filme. Noutras palavras, tomando as imagens-movimento ou o filme no seu conjunto, os diálogos acontecem em duas esferas diferentes: com os discursos que circulam na cultura da sociedade da qual se originou a produção ou na qual é realizada a exibição, e das imagens-movimento com outros elementos constitutivos da narrativa cinematográfica. Cabe aqui uma observação decisiva para nosso estudo: para que os diálogos possam ser realizados de forma mais

${ }^{14}$ Importa salientar que a análise, conforme a intenção para a qual está voltada - histórica ou educacional - privilegiará um dos focos de enunciação: ou o da época de produção, ou o da época de exibição. significativa e/ou com finalidades educacionais, é necessário que o público tenha construído representações que permitam uma formulação de discursos com os quais o filme se propõe a dialogar ou formular uma "reação responsiva". ${ }^{15}$

Uma visão bastante sumária das teses bakhtinianas e suas assertivas acerca dos processos dialógicos dos discursos e seus significados, cotejada com a argumentação de Mitry sobre a linguagem cinematográfica, fornecem-nos novas chaves para uma aventura pelo universo das relações entre história e cinema. Vejamos, pois, uma possibilidade de aplicação da argumentação que construímos, e seus resultados.

\section{Um filme em múltiplos diálogos com a história}

A abordagem metodológica de um filme somente pode ser realizada a partir de elementos escolhidos e recolhidos da obra, uma vez que ela é sempre "aberta" (Eco, 1991), mais ainda se considerarmos que a linguagem cinematográfica permite a reunião das demais linguagens. $\mathrm{O}$ limite de um artigo exige que sejam feitas restrições às escolhas, artifício que é inerente a qualquer exercício analítico. Nesse sentido, seria arriscado considerar que a abordagem de um filme venha a esgotar quaisquer possibilidades de um exercício como esse. A intenção que alimentou a iniciativa apresentada aqui se limita apenas a demonstrar possibilidades.

O filme escolhido como objeto deste estudo foi realizado pelo diretor Ridley Scott, distribuído e exi-

${ }^{15}$ A idéia de que os discursos têm origem nas representações foi sugerida por Chartier, ao afirmar que devemos "considerar estas representações como as matrizes de discursos e de práticas diferenciadas..." (1989, p. 18). Observe-se que, sejam as representações consideradas em quadros teóricos que a concebem como mais históricas e flexíveis (como em Norbert Elias), ou mais estáveis (como em Durkheim), isso não constitui impedimento ao emprego dos discursos como expressões destas, uma vez que os discursos e seus significados são tomados segundo sua enunciação em contextos sociocultural e historicamente situados. A respeito da discussão, consultar Malerba (2000, p. 199-225) e Geertz (1989, p. 188). 
bido em 1992. O diretor tem uma carreira na qual figuram filmes como Os duelistas, Gladiador, Cruzada, Alien - o oitavo passageiro, Thelma e Louise e Blade Runner - o caçador de andróides, além de $O s$ vigaristas, Hannibal e Todas as crianças invisiveis. A versatilidade de Scott compara-se ao trabalho primoroso da fotografia de seus filmes - sua formação básica - e acompanha o uso que faz da trilha sonora duas marcas indeléveis de sua filmografia. No Brasil, a película recebeu o título de 1492 - A conquista do paraíso, uma tradução literal do título original - 1492: Conquest of paradise. Apesar de o título sugerir que se trata do processo de "descoberta da América", o filme é construído como uma biografia de Cristóvão Colombo, que assim serve de mote ao cineasta e/ou realizadores para lidar propriamente com o tema muito difundido e visitado na época, pois sua exibição nos cinemas coincidiu com as comemorações dos 500 anos da viagem.

Colombo figura na película como o único protagonista de uma epopéia, retirando do contexto de época muitos dos fatores históricos que contribuíram decisivamente para a realização daquela empreitada. A estrutura do discurso, portanto, já transforma o filme em um problema, torna todo o filme uma questão a ser trabalhada pelo professor: uma análise crítica e ativa poderia dirigir suas perguntas para esclarecer os limites de um acontecimento histórico ser fruto, unicamente, da vontade de um homem. Vale observar que, como qualquer obra, um filme dialoga especialmente com o que Bakhtin chama de "comunicação cultural". Assim, um ambiente de mobilização e/ou transformação coletiva de uma sociedade não corresponderia ao contexto de diálogo da época de realização do filme - a contemporaneidade está mais para o individualismo e grandes ídolos -, muito ao contrário do momento histórico no qual se desenrola a trama, mesmo considerando que o período representado tem sido considerado um marco da emergência do individualismo no Ocidente. ${ }^{16}$

${ }^{16}$ A respeito dessa época, consultar Anderson (1995), Burckhardt (1991) e Delumeau (1983).

\section{A abertura e outras seqüências em diálogos com o conhecimento histórico}

1492 - A conquista do paraíso, em sua abertura, remete o público à época ${ }^{17}$ na qual se desenrolaram os acontecimentos, contextualizando historicamente de forma genérica e discutível, é verdade - a narrativa e o universo a partir do qual o discurso cinematográfico se vai constituir. São apresentados os créditos do filme, com imagens pictóricas como pano de fundo, seguidos da apresentação de um prólogo escrito, no qual há uma descrição sumária da época na Espanha. Acompanha essa abertura uma música de som ritmado, cadenciado, executado numa mistura de vozes (tribais/ópera?) e sons eletrônicos, sugerindo um sincretismo musical global. O diálogo aqui, mais sonoro que imagético, se trava com a produção musical da época e remete o público ocidental, simbolicamente, ao universalismo iniciado pelas descobertas da Era Moderna. Observe-se que os diálogos, novamente, se realizam nas duas dimensões contextuais sugeridas pelos argumentos de Bakhtin: o do filme e o da "comunicação cultural".

A abertura permite-nos observar a importância da trilha sonora na sua relação dialógica com as imagens e a trama; não somente no que diz respeito à capacidade que tem de inspirar emoção, mas, e principalmente, de atender a finalidades da narrativa cinematográfica, quando e se bem articulada aos demais elementos do filme. A música que acompanha a abertura do filme foi composta por um músico renomado - Vangelis - e provoca no público uma sensação de expectativa, de que estamos prestes a presenciar um acontecimento de extrema importância. Ela converte-se no contexto da narrativa em elemento central, torna-se uma aliada decisiva na construção dramática e na pretensão do cineasta/realizadores de

${ }^{17} \mathrm{O}$ contexto de época pode ser definido, sumariamente, como sendo o da região da Espanha, durante o século XV, em processo de constituição do Estado Nacional, no qual a expulsão dos muçulmanos da Península Ibérica culmina com a conquista de Granada em 1492. 
provocar emoções no público. O resultado poderia ser resumido como: a seqüência leva o público a experimentar uma sensação de emoção e expectativa, nascidas dos diálogos entre a mensagem escrita (violência e opressão), a música que reverbera - mais no corpo que nos ouvidos - e a cor vermelho-sangue que cobre a tela (referindo-se à ação cruel e sanguinária da Inquisição na Espanha da época, ou ao sangue derramado pelos europeus ao longo do processo de conquista da América, quem sabe?). Aqui, o contexto é absolutamente compósito e nos faz reconhecer o significado atribuído à "magia do cinema".

A primeira seqüência apresenta imagens-movimento em que Colombo está com uma laranja nas mãos; sentado numa praia, com o oceano ao fundo e ladeado por seu filho, de uma perspectiva da qual podemos "avistar" uma embarcação no horizonte. O título da película, a abertura com sons épicos, a apresentação de uma versão do contexto de época na Espanha e as imagens-movimento que apresentam visualmente uma esfera, o mar revolto e o oceano ao fundo, o figurino dos personagens e a imagem da embarcação abrem uma infinidade de diálogos com outros discursos que circulam e circulavam nos acervos culturais dos homens que tiveram uma formação escolar no Ocidente.

O cineasta (e/ou realizadores) sugere também, por meio das imagens, o que virá em seguida. Segundo esclarece-nos a argumentação de Jean Mitry (1989), as imagens têm nos filmes significados diferenciados daqueles que teriam no mundo da experiência, por terem sido escolhidas para figurar na tela. Voltando-nos para as teses de Bakhtin (1997), podemos considerar que os signos - nesse caso, as imagens que se tornaram signos ao serem apresentadas na tela, segundo o argumento de Mitry - têm sentido somente no contexto de sua enunciação (o filme), e ainda estão relacionados ao contexto sociocultural e histórico de produção e/ou de exibição que devem ser avaliados na análise. Vejamos então o filme nos dois contextos e alguns de seus possíveis diálogos com eles.

Observamos que diversos signos foram introduzidos na narrativa: o oceano, a embarcação, uma la- ranja - uma esfera. Elementos que também obedecem à estratégia de construção do discurso cinematográfico, mas, nesse caso, são explícitos em suas propostas de diálogos. O diálogo proposto pelo discurso cinematográfico trava-se com os discursos da história ocidental, especificamente o processo denominado "expansionismo marítimo europeu", que consta em qualquer livro de história. Recorrendo a Chartier (1989, p. 13-28), concluiríamos que esses elementos são signos que remetem os sujeitos que assistem ao filme à representação que a sociedade contemporânea construiu daquele momento histórico. Resumindo e reportando-nos às proposições de Bakhtin (1992), os realizadores, ao recorrerem àqueles signos para construir seu discurso-filme, dialogam com os discursos históricos consolidados dessa sociedade - da “comunicação cultural” na qual eles também estão inseridos; o filme promove uma "reação responsiva" aos discursos consolidados dos indivíduos que compõem o público, que podem concordar e incorporar o filme como a "sua" representação de época, ou reagir, buscando resistir ao discurso cinematográfico, contestando ou até ignorando a interpelação proposta pela película.

O cineasta (e/ou realizadores) recorreu ao repertório que a comunicação cultural disponibilizou no contexto contemporâneo e, reconhecendo esses discursos, formulou signos - a partir das imagens capturadas do mundo, como diz Mitry (1989) - que se referem a eles. Inseriu-os na tela, compondo a narrativa fílmica, constituindo seu próprio discurso. Nessas mesmas circunstâncias, um outro cineasta poderia recorrer a outras imagens, a outros "signos" com a mesma finalidade - de servir à construção da sua narrativa. Um olhar informado e atento apreende imediatamente todos esses signos que o diretor/realizadores oferece(m) na película, mas seus desdobramentos cognitivos - nas interpretações que se constroem da história na ou para a construção de conhecimentos - dificilmente podem ser mensurados.

A seguir, na mesma seqüência, Colombo pede a seu filho que observe uma embarcação que navega oceano adentro, e vai descrevendo verbalmente o que 
observamos cinematograficamente: o desaparecimento progressivo da embarcação. Assim, o cineasta, antes mesmo da fala do personagem, já construiu um discurso cinematográfico que permitiria, a um bom observador, inferir sobre a questão abordada na seqüência. O diálogo proposto pelo discurso cinematográfico refere-se à maneira como, a partir daquela época, passam a ser observados e concebidos os fenômenos, empregando a razão para explicálos: nesse caso, a esfericidade da Terra, tal qual a da laranja.

O diálogo constrói-se no campo do conhecimento histórico propriamente dito, pois o público para o qual o filme se dirige seria composto por pessoas que freqüentam os cinemas e/ou as locadoras de filmes; pessoas que, supostamente, concluíram a educação de nível fundamental e, por isso, reconhecem que a esfericidade da Terra era um conhecimento "recente" naquela época. Noutras palavras, sabem que a esfericidade da Terra não era, ainda, universalmente reconhecida, e as viagens pelo "mar oceano" eram consideradas ameaçadoras. Nessa medida, podemos dizer que as vozes do discurso cinematográfico e histórico se interanimam mutuamente. $\mathrm{O}$ dialogo aqui é tão evidente que dispensa uma análise mais demorada. No entanto, numa sala de aula na qual os alunos não conhecessem essas peculiaridades históricas, essas seqüências do filme seriam desconsideradas. Nesse sentido, o papel fundamental do professor poderia limitar-se a tornar evidente, esclarecer a pretensão dos realizadores nessa passagem do filme - dialogarem, ou mais precisamente, provocarem "reação responsiva" no público.

Uma outra seqüência que elucida possibilidades da aplicação teórico-metodológica que defendemos é a da sabatina à qual Colombo se submete na Universidade de Salamanca acerca de seu arrojado projeto. Nela não são as imagens os elementos cinematográfícos que interpelam o público, mas são os próprios diálogos entre os personagens da película que instigam reações responsivas. Nas discussões que se travam entre Colombo e seus argüidores aparecem os discursos das concepções científicas que se confron- tavam na época: a visão católica, ainda baseada nas teses de Ptolomeu, e as novas teses renascentistas sobre o universo. Verifica-se a riqueza dessa discussão, não somente para esclarecer e informar sobre essas concepções, mas para a compreensão dos processos, das disputas históricas que se constituíram em torno dela, dos interesses envolvidos e da condição que tem a Igreja católica no contexto da época.

Algumas questões que são apresentadas pelo discurso cinematográfico provocam (ou permitem que observemos a intenção de provocar) reações responsivas no público. Elas referem-se à composição do comitê "científico" que decidiu sobre a viagem; dos motivos de sua composição contar com representantes da monarquia espanhola e da Igreja católica; da discussão sobre o poder daqueles que detêm o conhecimento; das relações entre a crise que a Igreja passou naquela época com a perda desse poder.

Os diálogos são inúmeros e as reações responsivas prendem-se ao contexto de enunciação e ao repertório que o público apresenta no momento da exibição - o da comunicação cultural -, ou seja, dependendo do conhecimento histórico e da extensão da crítica do público, uma infinidade de elementos ligados aos processos humanos que envolvem as relações de poder e interesse é interpelada e pode ser explorada pedagogicamente. Os diálogos podem levar, por exemplo, a um questionamento do significado que têm aqueles homens ou aquelas instituições que se arrogam o direito de deter o conhecimento, e que reflexos isso tem nas relações de poder em todas as épocas, e mesmo atualmente.

Na mesma seqüência da Universidade de Salamanca, Colombo contra-argumenta ao representante da Igreja que a conquista das Índias seria uma forma de expandir a fé cristã, e ao argüidor representante da monarquia diz que poderia trazer riquezas à Espanha e torná-la não um reino, mas um império. O jogo de cena é muito instigante e significativo porque Colombo, ao sentir-se acuado pelas perguntas de um e outro, procura recorrer aos interesses que cada um deles poderia reconhecer na sua empreitada. O navegador busca apoio na própria disputa que se travava 
entre esses agentes sociais naquela época, num cenário histórico mais amplo.

Observamos que a interanimação das vozes que o filme permite é muito mais rica se o conhecimento histórico e/ou o repertório cultural ao qual o público puder recorrer para apreendê-la e problematizá-la, em toda a sua dimensão, forem suficientemente elaborados. Uma ação no sentido de problematizar a seqüência, evidenciando e/ou esclarecendo o contexto de época na Espanha, os interesses e as disputas dos envolvidos no processo histórico do qual emergiu o debate, iluminaria o diálogo que o filme pretende estabelecer e a interanimação de vozes promovida entre os discursos fílmico e histórico.

Numa outra seqüência, Colombo está a caminho de casa quando chega a uma praça em busca do filho e aí presencia (visualmente, compartilhando com o público a cena) a execução de hereges católicos pela Inquisição. Nessa seqüência, o cineasta (e/ou realizadores) também buscou um diálogo com o conhecimento histórico; no entanto, para estabelecer a reação responsiva ou uma ação mais pedagógica (mais voltada para a construção de conhecimentos propriamente históricos) com relação à época na qual se passa a trama, seria necessário mais conhecimento por parte do público. Nessas imagens-movimento são representados os rituais de execução característicos da Inquisição, com detalhes sobre os métodos de punição impostos aos hereges enforcamento e depois fogueira para os arrependidos, ou somente fogueira para aqueles que não se arrependessem, que, nesse caso, eram queimados vivos. O impacto que a visão da cena provoca é enorme. ${ }^{18}$

A abordagem da seqüência demonstra que o emprego de filmes como mediadores na construção de conhecimentos históricos demanda que o contexto discursivo seja rico em discursos sobre a história que venham a propiciar diálogos mais elaborados com o discurso cinematográfico. Também evidencia a importância da ação do professor e como uma mesma seqüência pode ou não se tornar mediadora nos pro-

${ }^{18}$ Aqui me refiro às reações observadas em diferentes grupos para os quais tive oportunidade de exibir o filme. cessos de ensino-aprendizagem - podendo ou não ser empregada como ferramenta cultural nos processos de construção do conhecimento histórico (ou outros mais), dependendo da ação do professor e/ou do conhecimento do público. Nesse caso, duas possibilidades apresentaram-se: uma na qual os métodos inquisitoriais se converteriam em informação - mera curiosidade histórica -, e outra que empregasse o impacto visual de sua representação na tela para abrir uma infinidade de questões sobre essa instituição, dialogando com o conhecimento histórico - de época e/ ou contemporâneo -, contribuindo não somente para a construção de conhecimentos, mas também para a formulação de discussões acerca da cidadania, do poder, das relações e ações políticas, sociais, econômicas e culturais.

\section{Muito mais que "erros" e "acertos"}

Uma outra seqüência do filme, muito elucidativa para nosso exercício, é aquela em que Colombo entra em casa e imediatamente se encaminha para um canto do cômodo, onde existe uma espécie de lavabo estilizado. Depois de lavar as mãos e enxugá-las, completando a assepsia, encaminha-se para sua esposa para lhe dar a notícia de que conseguiu uma audiência com o Conselho do Rei, na Universidade de Salamanca.

A seqüência pareceria absolutamente normal, até "didática", não fosse seu anacronismo absoluto: sabemos que a assepsia só foi incorporada, mesmo nas práticas médicas ocidentais, no século XIX, e que os hábitos daquela época certamente não podiam ser esses; um lavabo, mesmo que pequeno, e a preocupação com assepsia seriam coisas impensáveis numa casa da época. Ela permite-nos constatar a historicidade do filme - como sugerem as considerações de Marc Ferro (1992; 1979) - apresentando uma contrahistória, na medida em que um hábito contemporâneo é representado em um filme que pretende retratar uma época.

A seqüência revela também que a representação de um hábito contemporâneo projetado para o passado (re)construído pelo filme só tem significado no con- 
texto de sua produção (também de leitura). Segundo as considerações de Chartier (1989), só aí teria seu significado apreendido pelo público. Se confrontarmos o discurso cinematográfico com outros discursos da época que o filme (re)constrói, torna-se incontestável o fato de que não eram esses os hábitos daquele tempo. Analisado sob as proposições bakhtinianas, o discurso cinematográfico dialoga com outros discursos da contemporaneidade ao cometer esse anacronismo. Noutras palavras, ao dialogar com discursos do seu contexto de enunciação - o contemporâneo, no qual seu significado pode ser apreendido -, a seqüência denuncia a historicidade do filme. Ao ser confrontada com discursos da época que propõe representar na tela, a seqüência apresenta-se como um erro, uma desinformação, um desconhecimento histórico.

A cena permite que façamos comentários sobre duas importantes questões acerca do emprego de filmes como ferramenta cultural nesses processos: a ação do professor para esclarecimento do problema não exige dele um profundo conhecimento de época, como ocorre com outras questões apontadas em outras análises, o que seria uma exigência exagerada,${ }^{19}$ mas, em contrapartida, evidencia como as obras humanas estão imersas nos seus contextos históricos e as dificuldades de escaparem da sua historicidade. Assim, mais do que apresentar um "erro" histórico, o professor poderia explorar o problema para dar significado à disciplina, contribuindo para o esclarecimento de questões relacionadas a outras disciplinas.

\section{Imagens-movimento e os dois contextos dialógicos}

Nesse momento da exposição vamos voltar o foco de análise para uma imagem-movimento que, fora do contexto fílmico e sem um diálogo com o conhecimento histórico, seria absolutamente desprovida de

${ }^{19}$ Vale lembrar que as produções cinematográficas de qualidade que lidam com contextos de época sempre mantêm um especialista como consultor. Assim, seria um disparate exigir de um professor que ele conhecesse em detalhes todas as épocas abordadas por filmes. Em contrapartida, uma análise que buscasse reconhecer significado. A imagem-movimento consiste em uma mão que segura uma garrafa de vinho e se dirige a um cálice mais distante, faz que vai verter vinho nele, suspende o ato, retorna a um cálice mais próximo e, aí sim, serve o vinho. A imagem-movimento, apreciada "isoladamente", não tem qualquer significado além desse. Mas, ao ser inserida no seu contexto do filme, passa a "interanimar" a voz do cineasta/realizadores com o restante das vozes apresentadas no discurso cinematográfico, e também com as vozes do discurso histórico. Vejamos, pois, a mesma imagemmovimento dialogando com seu contexto de enunciação mais próximo, o fílmico, e mais amplo, o do conhecimento histórico.

A seqüência inicia-se com a chegada do representante da monarquia à mesa do representante da Igreja, num ambiente que nos sugere o "refeitório" da Universidade de Salamanca. A situação desenrola-se com discussões sobre a viagem de Colombo e os interesses envolvidos dessas instituições, culminando com a imagem-movimento que descrevemos anteriormente. A "mão" que figura na imagem-movimento é do personagem que representou a monarquia na seqüência em que Colombo expõe seus argumentos na universidade. O outro personagem, de quem é o cálice "não servido", é o representante da Igreja que o acompanha numa refeição com pães e vinho. A descrição contextualizada da imagem-movimento seria então: na discussão ocorrida no "refeitório" entre os representantes da Coroa e da Igreja, acerca da viagem de Colombo, são apresentadas as disputas de interesses entre a monarquia e a Igreja, cena na qual observamos que o representante da monarquia interrompe a ação de "servir" vinho ao representante da Igreja. $^{20}$

tais detalhes estaria mais próxima de uma história factual, tão distante dos objetivos e trabalhos da historiografia contemporânea.

${ }^{20}$ A seqüência também apresenta falas dos personagens que reforçam a interpretação que formulamos. No entanto, nossa intenção é evidenciar suas características imagéticas e a importância que essas têm num filme, bem como demonstrar a operacionalidade metodológica das teses bakhtinianas para analisar a linguagem cinematográfica. 
A imagem-movimento apresenta um significado tão importante quanto outras seqüências completas do filme. Ao dialogar com os discursos que compõem o conhecimento histórico, não só apresenta disputas históricas ocorridas na Espanha por essa época, como, de maneira metafórica, sugere o desfecho dessas disputas entre a monarquia e a Igreja. O cineasta diz-nos, "metaforicamente" - por meio de imagens-movimento - que a monarquia, que até então "servia" à Igreja, está em vias de não "lhe servir" mais. Ao contrário, como atestam os estudos históricos, é a Igreja que passará a servir à monarquia como ferramenta na consolidação do Estado absolutista espanhol, pelo "aparelho ideológico" da Inquisição (Anderson, 1995).

Essas reflexões demonstram, com clareza, como as teses de Bakhtin podem ser aplicadas na realização de uma leitura de filmes: é possível perceber como, em um discurso cinematográfico, uma imagem-movimento estabelece diálogo com seu contexto mais imediato - o filme -, e com um contexto mais amplo - o da comunicação cultural; nesse caso, o contexto configurado pelos discursos da história. É fácil concluir que o reconhecimento desse diálogo amplia, decisivamente, o significado que se poderia atribuir à imagem-movimento, considerando-se somente o contexto fílmico. Outra observação importante é que a imagem-movimento que foi foco de nossa análise e que formula um diálogo com os discursos da história poderia estar realizando o mesmo processo com outros discursos - políticos, filosóficos, científicos ou culturais da época representada no filme ou da época na qual foi realizada a produção.

Finalmente, é preciso reconhecer que o fascínio pelo cinema ou uma boa representação - seja de época ou temática - não bastam para o envolvimento de um filme em qualquer processo de ensino-aprendizagem. A qualidade de uma obra cultural sempre deve ser avaliada, mas deve-se cuidar, sobretudo, para que o discurso cinematográfico não se converta em "verdade" (nem mesmo um documentário), uma vez que é característico dos seus dispositivos levar o público a esse tipo de percepção. Assim, para poder ser em- pregado como uma ferramenta cultural, um filme deve ser problematizado, não somente no se refere ao seu conteúdo, como em suas estratégias narrativas e de convencimento. Nesse sentido, parece fundamental que, concebendo a escola como um ambiente de reflexão crítica sobre os valores veiculados pelas mídias, sempre se leve em consideração o caráter das mensagens que elas oferecem.

\section{Ficha técnica do filme}

1492 - A conquista do paraíso, de 1992, dirigido por Ridley Scott e co-produzido por França, Espanha e Estados Unidos. Com: Gérard Depardieu (Cristóvão Colombo), Armand Assante (Sanchez), Sigourney Weaver (Rainha Isabel), Loren Dean (Fernando), Ángela Molina (Beatrix), Fernando Rey (Marchena), Michael Wincott (Moxica), Tchéky Karyo (Pinzon), Kevin Dunn (Capitão Mendez), Frank Langella (Santangel), Mark Margolis (Bobadilla), Kario Salem (Arojaz), Billy L. Sullivan (Fernando - 10 anos).

\section{Referências bibliográficas}

ANDERSON, Perry. As linhagens do Estado absolutista. Trad. João Roberto Martins Filho. São Paulo: Brasiliense, 1995.

BAKHTIN, Mikhail. Gêneros do discurso. In: Estética da criação verbal. Tradução do francês Maria Ermantina Galvão Gomes Pereira. São Paulo: Martins Fontes, 1992.

. (Volochinov). Marxismo e filosofia da linguagem. Trad.

Michel Lahud e Yara Frateschi Vieira. São Paulo: Hucitec, 1997.

O discurso no romance. In: Questões de

literatura e de estética. Trad. do russo Aurora Fornoni Bernadini et al. São Paulo: UNESP/Hucitec, 1998.

BURCKHARDT, Jacob. A cultura do Renascimento na Itália. Trad. Vera Lucia de Oliveira Sarmento e Fernando de Azevedo Correa. São Paulo: Companhia das Letras, 1991.

BURGOYNE, Robert. A nação do filme. Trad. René Loncan. Brasília: Editora Universidade de Brasília, 2002.

BURKE, Peter (Org.). A escrita da história: novas perspectivas. Trad. Magda Lopes. São Paulo: UNESP, 1992.

CERTEAU, Michel de. A escrita da história. 2. ed. Trad. Maria de Lourdes Menezes Rio de Janeiro: Forense Universitária, 2000.

CHARTIER, Roger. A história cultural: entre práticas e representações. Trad. Maria Manuela Galhardo. Lisboa/São Paulo: Difel, 1989. 
.(Org.) . Práticas da leitura. Trad. Cristiane Nascimento. Rio de Janeiro: Estação Liberdade, 2001.

DELUMEAU, Jean. A civilização do Renascimento. Trad. Manuel Ruas. Lisboa: Estampa, 1983.

ECO, Umberto. A obra aberta: formação e indeterminação nas poéticas contemporâneas. Trad. Giovanni Cutolo. São Paulo: Perspectiva, 1991.

. Interpretação e superinterpretação. Trad. MF; revi-

são tradução e texto final Monica Stahel. São Paulo: Martins Fontes, 1997.

FERRO, Marc. Cinema e história. Trad. Flavia Nascimento. Rio de Janeiro: Paz e Terra, 1992.

GEERTZ, Clifford. A interpretação das culturas. Rio de Janeiro: Livros Técnico Científicos Editora S/A, 1989.

MAINGUENEAU, Dominique. Análise de textos de comunicação. Trad. Cecilia P. de Souza e Silva e Décio Rocha. São Paulo: Cortez, 2001.

MALERBA, Jurandir. Para uma teoria simbólica: conexões entre Elias e Bourdieu. In: CARDOSO, Ciro Flamarion; MALERBA; Jurandir (Orgs.). Representações: contribuição a um debate transdisciplinar. Campinas: Papirus, 2000. p. 199-254.

METZ, Christian. Linguagem e cinema. Trad. Marilda Pereira. São Paulo: Perspectiva, 1980.

MITRY, Jean. Estética y psicología del cine. 4. ed. 2 v. Trad. Rene Palacios More. Mexico: Siglo XXI de Espanha, 1989.

ROSENSTONE, Robert. El pasado en imágenes: el desafío del cine a nuestra idea de la historia. Trad. Sergio Alegre. Barcelona: Ariel, 1997.

STAM, Robert. Bakhtin: da teoria literária à cultura de massa. Trad. Heloisa John. São Paulo: Ática, 1992.

VYGOTSKY, Lev Semyonovich. Pensamento e linguagem. Trad. Jeferson Luiz Camargo; revisão técnica Jose Cipolla Neto. São Paulo: Martins Fontes, 1993.

. A formação social da mente. Trad. Jose Cipolla Neto,

Luiz Silveira Menna Barreto, Solange Castro Afeche. São Paulo: Martins Fontes, 1994.

WERTSCH, James V. Vygotsky y la formación social de la mente.
Trad. Javier Zanón e Montserrat Cortés. Barcelona: Paidós Iberica, 1988. Voces de la mente. Madrid: Visor Distribuiciones, 1993. . A voz da racionalidade em uma abordagem sociocultural da mente. In: DEL RIO, Pablo; ÁLVARES, Amelia (Orgs.). Estudos socioculturais da mente. Trad. Maria da Graça Gomes Paiva, Andre Rossano Teixeira Camargo; consultoria, supervisão e revisão técnica desta edição Maria da Graça Gomes Paiva. Porto Alegre: Artmed, 1998. p. 107-121.

La mente em acción. Buenos Aires: Aique Grupo Editores, 1999.

. Voices of collective remembering. Cambridge:

Cambridge University Press, 2002.

ROBERTO ABDALA JUNIOR, mestre em educação e doutorando em história pela Universidade Federal de Minas Gerais (UFMG), é professor no Centro Universitário do Leste de Minas Gerais, nos cursos de história e pedagogia. Publicações recentes: "O Brasil dos anos 1990: ação política, tele-ficção e as lutas pela memória" (In: SIMPÓSIO NACIONAL DE HISTÓRIA, 24., 2007, Anais. São Leopoldo: Associação Nacional de História - ANPUH, 2007. 1 CD-ROM); "O cinema é outra história: considerações sobre o emprego de filmes nas aulas de história" (In: ENCONTRO NACIONAL DOS PESQUISADORES NO ENSINO DE HISTÓRIA, 7., 2006. Anais. Belo Horizonte: s.ed., 2006. 1 CD-ROM); "História e cinema em diálogo: um estudo sobre a repercussão da exibição de filmes em turmas do Curso de História" (In: CONGRESSO INTERNACIONAL DE LINGUAGEM E COGNIÇÃO, 2., 2003. Belo Horizonte: s.ed. 1 CD-ROM). Pesquisa de doutorado em andamento: "O Brasil dos anos 1990: a minissérie Anos Rebeldes, ação política e as lutas pela memória da ditadura”. $E$ mail: abdalajr@gmail.com

Recebido em maio de 2007 Aprovado em julho de 2007 
Palavras-chave: história; cinema; construção do conhecimento histórico

The cinema in the conquest of America: a film and its dialogues with history

The article seeks to deal with a classical question, particularly present in the relation between teachers and filmmakers: films and processes of learning. Based on works by James Wertsch, a psychologist who has been searching for "approaches" between the theses of Vygotsky and Bakhtin, these reflections aim to demonstrate that the arguments of these and other authors who study the cinema-also from the Bakhtinian perspective - can be articulated in the sense of suggesting strategies for using films in the process of constructing historical knowledge. Finally, we propose a practical exercise based on the film 1492 - The conquest of paradise, by Ridley Scott.

Roberto Abdala Junior

O cinema na conquista da América: um filme e seus diálogos com a história

$\mathrm{O}$ artigo procura lidar com uma questão clássica, especialmente presente entre professores e cineastas: os filmes e os processos de aprendizagem. Baseado em trabalhos de James Wertsch, psicólogo que vem buscando encontrar "aproximações" entre as teses de Vygotsky e Bakhtin, as reflexões buscam demonstrar que os argumentos desses e de outros autores que estudam o cinema - também pelo viés bakhtiniano - podem ser articulados no sentido de sugerir estratégias para empregar filmes nos processos de construção do conhecimento histórico - escolar ou não. Ao final, a partir do filme 1492 A conquista do paraíso, de Ridley Scott, propomos um exercício prático que operacionaliza a argumentação formulada anteriormente.
Key words: history; cinema; construction of historical knowledge

El cine en la conquista de América: una película y sus diálogos con la historia

El artículo busca trabajar con una cuestión clásica, presente especialmente entre profesores y cineastas: las películas y los procesos de aprendizaje. Basados en trabajos de James Wertsch, psicólogo que viene buscando encontrar "aproximaciones" entre las tesis de Vygotsky y Bakhtin, las reflexiones buscan demostrar que los argumentos de esos y otros autores que estudian el cine - también bajo el mirar bakhtiniano - pueden ser articulados en el sentido de sugerir estrategias para emplear películas en los procesos de construcción del conocimiento histórico - escolar o no. Al final, a partir de la película 1492 La conquista del paraíso, de Ridley Scott, proponemos un ejercicio práctico que realiza la argumentación formulada anteriormente. 
Resumos/Abstracts/Resumens

Palabras claves: historia; cine; construcción del conocimiento histórico 